\title{
The Relationship Of Mental Thoughness And Competitive Anxiety With Karate Referee Performance
}

\author{
Rahayu Lestari ${ }^{1)}$, Adi Rahadian ${ }^{2)}$, Aziz Amrulloh ${ }^{3)}$, Muhamad Syamsul Taufik ${ }^{4)}$ \\ Pendidikan Jasmani Kesehatan dan Rekreasi \\ Fakultas Keguruan dan Ilmu Pendidikan, \\ 1,2,3,4 Universitas Suryakancana, Jawa Barat, Indonesia \\ Email : ${ }^{1}$ Rahayu@gmail.com, ${ }^{2}$ adira@ unsur.ac.id, ${ }^{3}$ aziz@ unsur.ac.id, ${ }^{4}$ syamsultaufik@unsur.ac.id
}

\begin{abstract}
This study aims to determine: (1) To find out whether there is a significant relationship between mental toughness and referee karate performance, (2) To find out if there is a significant relationship between competitive anxiety and referee karate performance and (3) To find out whether there is significant relationship between mental toughness and competitive anxiety with the performance of karate referees. The research method used is a qualitative approach with a descriptive method that uses 15 karate referees (kumites) that are licensed by the national college through a questionnaire. Data analysis techniques using descriptive data analysis techniques while the calculation in a questionnaire using Microsoft Excel and SPSS. Based on the results of this study show that based on the analysis it can be seen that the relationship between mental toughness and competitive anxiety with the referee's performance is significant in other words the relationship is large and very influential when leading the match.
\end{abstract}

Keywords: Competitive Anxiety, Mental Toughness, Karate Referee Performance

\section{Hubungan Mental Thoughness dan Competitive Anxiety Terhadap Performa Wasit Karate \\ ABSTRAK}

Penelitian ini bertujuan untuk: (1) Untuk mengetahui apakah ada hubungan yang signifikan antara mental thoughness dan kinerja karate wasit, (2) Untuk mengetahui apakah ada hubungan yang signifikan antara competitive anxiety dan kinerja karate wasit dan (3) Untuk mengetahui apakah ada hubungan yang signifikan antara mental thoughness dan competitive anxiety dengan kinerja wasit karate. Metode penelitian yang digunakan adalah pendekatan kualitatif dengan metode deskriptif yang menggunakan 15 wasit karate (kumite) yang dilisensi oleh perguruan tinggi nasional melalui kuesioner. Teknik analisis data menggunakan teknik analisis data deskriptif, dengan penghitungan kuesioner menggunakan Microsoft Excel dan SPSS. Berdasarkan hasil penelitian ini menunjukkan bahwa terdapat hubungan signifikan antara competitive anxiety dan competitive anxiety dengan kinerja wasit, dengan kata lain hubungan itu besar dan sangat berpengaruh ketika memimpin pertandingan.

Kata kunci: Mental Toughness, Competitive Anxiety, Performa Wasit Karate

Info Artikel

Dikirim

Diterima

Dipublikasikan
: 6 Oktober 2020

: 31 Oktober 2020

: 12 November 2020
(C) 2020 IKIP BUDI UTOMO MALANG

P-ISSN 2613-9421

E-ISSN 2654-8003

\ Alamat korespondensi: syamsultaufik@unsur.ac.id

Universitas Suryakancana, Jl. Pasirgede Raya, Bojongherang, Kec. Cianjur, Kabupaten Cianjur, Jawa Barat 43216 Indonesia 
Rahayu Lestari' ${ }^{1)}$, Adi Rahadian ${ }^{2)}$, Aziz Amrulloh ${ }^{3)}$, Muhamad Syamsul Taufik ${ }^{4)}$. Jp.jok (Jurnal Pendidikan. Jasmani,

\section{PENDAHULUAN}

Olahraga merupakan suatu bentuk aktivitas fisik yang terencana dan terstruktur yang melibatkan gerakan tubuh berulang-ulang dan ditujukan untuk meningkatkan kebugaran jasmani. Selain itu, olahraga juga mempunyai makna sebagai aktivitas spontan yang dilakukan secara bebas dengan mencari waktu luang untuk pergerakan tubuh demi menjaga kesehatan jasmani dan rohani olahraga sebagai penunjang suatu prestasi, bahkan dijadikan sebagai suatu profesi. Dikemukakan oleh (Rahadian \& Suryakancana, 2020) bahwa olahraga telah disetujui oleh masyarakat sebagai penunjang untuk memperoleh hidup sehat dan bugar. (Sorate, 2016) Sport is a spontaneous activity that is carried out freely by finding free time for body movements to maintain the physical and spiritual health of every human being, which later the body will feel light and fresh, with the help of oxygen supply to the brain is not obstructed.

Perkembangan olahraga karate di Indonesia begitu pesat dengan terbentuknya beberapa aliran dan dojo karate. (Laporte \& Lepresle, 2017) A traditional martial art from Japanese is Karate. Olahraga Karate sangatlah menarik bagi individu - individu yang menggemari olahraga kontak fisik (body contact). Cabang olahraga Karate berguna untuk membeladiri, melindungi diri, melindungi orang lain, menjaga kebugaran, menjaga kesehatan, dan sebagai penunjang untuk meraih prestasi.

(Carlos et al., 2019) in a match it is very necessary to have a match. Dalam suatu pertandingan Karate sangat dibutuhkan peranan seorang wasit untuk memimpin pertandingan dan menghasilkan atlet-atlet yang berkualitas. Menurut (Kuswoyo et al., 2017) bahwa wasit adalah seseorang yang mempunyai tugas untuk mengatur jalannya suatu pertandingan dengan baik sesuai prosedur yang telah ditentukan. Dengan saat ini bahwa berpandangan (Jatra \& Fernando, 2019) menjelaskan bahwa faktor sosial, psikologis dan lingkungan dapat berdampak pada kompetensi wasit pada saat proses pengambilan keputusan. Wasit dituntut untuk bisa memimpin pertandingan dengan baik dan berjalan dengan lancar sesuai harapan. Oleh karena itu, wasit harus memiliki mental toughness yang tinggi atau bagus. Seorang wasit diperlukan persiapan mengarah ke fisik, taktik, teknik, dan mental yang baik. Kesiapan terbagi menjadi beberapa bagian, salah satunya yaitu 
kesiapan mental. Menurut (Firmansyah, 2018) agar seseorang dapat melakukan penampilan yang optimal, dengan berbagai-faktor kesiapan dan keadaan mental yang baik pada diri seseorang tersebut. Selain dituntut untuk memiliki mental yang baik, seorang wasit wajib memiliki konsentrasi yang baik. (Teori, 2017) menjelaskan bahwa konsentrasi adalah hal yang diperlukan wasit untuk dapat memfokuskan pikirannya agar pada saat memimpin pertandingan bisa mendapatkan performa yang baik dan tidak memalukan karena adanya kesalahan. Untuk bisa meningkatkan mental toughness yang baik pada wasit, dengan dibutuhkan motif untuk mendorong semangat seorang wasit agar mencapai tujuan. Pandagan ini juga dikemukan oleh (Kristiyanto, 2017) motif merupakan pemacu dalam diri seseorang sebagai penggerak untuk dapat mengarahkan pada suatu tujuan.

Selain mental toughnes, terdapat pula competitive anxiety yang berkaitan dengan Kemampuan seorang wasit pada saat memimpin pertandingan. Competitive anxiety berkaitan dengan suatu rasa cemas atau kecemasan. Menurut (Kumar, 2016) kecemasan adalah suatu hal yang dirasakan seseorang berupa perasaan gelisah, gundah dengan disertai kegelisahan dan ketidakpastian. (Jatmika \& Mulia, 2019) Kecemasan yang sering dirasakan oleh wasit saat sebelum hingga saat memimpin pertandingan dikarenakan ketegangan yang mengakibatkan penurunan konsentrasi. Menurut (Setiawan \& Jannah, 2018) kecemasan adalah suatu pemikiran buruk yang akan menimpa dirinya dan diiringi dengan adanya perasaan cemas, gelisah, khawatir pada saat memimpin pertandingan. Kemampuan yang baik atau buruk seorang wasit di lapangan akan mempengaruhi keadaan psikologis wasit tersebut khususnya pada perasaan seperti kecemasan. Seorang wasit harus memiliki sikap optimis agar dapat memimpin pertandingan dengan lancar sesuai harapan.

Mental toughness dan competitive anxiety sangat berhubungan dengan performa wasit karate. (Jose \& Joseph, 2018) performance is the achievement of organizational goals that can form quantitative and qualitative outputs, creativity, flexibility, dependability or other things that can be desired by the organization. Menurut penadangan (Natalia et al., 2019) Kinerja merupakan suatu hasil dari penampilan yang dilakukan oleh seseorang.(Vaquera \& Ibáñez, 2020) Good or 
Rahayu Lestari' ${ }^{1)}$, Adi Rahadian ${ }^{2)}$, Aziz Amrulloh ${ }^{3)}$, Muhamad Syamsul Taufik ${ }^{4)}$. Jp.jok (Jurnal Pendidikan. Jasmani,

not the referee's performance will be determined by mental toughness with competitive anxiety.

\section{METODE}

Metode yang digunakan dalam penelitian ini menggunakan metode penelitian deskriptif dengan analisis korelasi. Dikemukakan oleh (Ivinson, 2001) dapat disimpulkan bahwa penelitian korelasi terkadang termasuk ke dalam penelitian deskripsi, karena penelitian tersebut dapat menggambarkan hal yang sudah terjadi. Adapun langkah penelitian didahului dengan observasi masalah, perencanaan, pelaksanaan, analisis, dan menyimpulkan hasil penelitian dengan jumlah subjek partisipan populasi 15 orang dengan dengan teknik pengambil sampel menggunakan total sampling yaitu 15 orang karena kurang dari 100 orang sehingga seluruh populasi dijadikan sampel. Adapun instrumen penelitian yang digunakan dalam penelitian ini adalah instrumen Competitive State Anxiety Inventory/CSAI-2 (Tangkudung,2018) terdiri atas 40 pertanyaan/pernyataan. Analisis dan deskripsi data yang dilakukan adalah menganalisis serta mendeskripsikan angka-angka yang merupakan hasil penghitungan statistik. Angka atau nilai yang dihasilkan bisa dibandingkan dengan angka tabel atau dideskripsikan secara langsung dengan berbagai pertimbangan dan ketentuan statistik Teknik yang digunakan untuk menganalisis data ada dua, yaitu analisis data kuantitatif dan analisis data kualitatif. Analisis data kuantitatif digunakan untuk membandingkan hasil dari penelitian yang telah dilakukan dengan menggunakan statistik. Sedangkan untuk analisis data kualitatif menggunakan analisis nonstatistik (berupa kata-kata), yaitu dengan mendeskripsikan data dan memberikan makna terhadap isi data tersebut, analisis data hubungan mental toughness dan competitive anxiety dengan performa wasit karate menggunakan SPSS 26. 


\section{HASIL DAN PEMBAHASAN}

Penelitian ini bertujuan untuk melihat hubungan mental toughness dan competitive anxiety dengan performa wasit karate (kumite). Penyajian data hasil penelitian berkenaan dengan 1) Gambaran umum variabel mental toughness 2) Gambaran umum variabel competitive anxiety dan 3) Gambaran variabel performa wasit karate (kumite).

Tabel 1. Tabel Mental Toughness

\begin{tabular}{llcr}
\hline Kriteria & Interval & Frekuensi & Prosentase \\
\hline Tinggi & $4.01-5.00$ & 9 & 60.00 \\
Sedang & $3.01-4.00$ & 5 & 30.00 \\
Rendah & $0.01-3.00$ & 1 & 10.00 \\
Jumlah & & & 100.00 \\
\hline
\end{tabular}

Hasil penelitian menunjukkan bahwa gambaran umum mental toughness diperoleh $60 \%$ berada pada kategori tinggi, $30 \%$ berada pada kategori sedang, dan $10 \%$ berada pada kategori rendah. Hal ini menunjukkan bahwa secara umum mental toughness wasit berada pada kategori tinggi.

Tabel 2. Tabel Competitive Anxiety

\begin{tabular}{llll}
\hline Kriteria & Interval & Frekuensi & Prosentase \\
\hline Tinggi & $4.01-5.00$ & 7 & 30.00 \\
Sedang & $3.01-4.00$ & 5 & 60.00 \\
Rendah & $0.01-3.00$ & 3 & 10.00 \\
Jumlah & & & 100.00 \\
\hline
\end{tabular}

Hasil penelitian menunjukkan bahwa gambaran umum competitive anxiety diperoleh $30 \%$ berada pada kategori tinggi, 60\% berada pada kategori sedang, dan $10 \%$ berada pada kategori sedang. Hal ini menunjukkan bahwa secara umum competitive anxiety wasit berada pada kategori sedang menunjukkan bahwa lebih banyak wasit yang memiliki competitive anxiety tinggi. 
Tabel 3. Tabel Performa Wasit

\begin{tabular}{llcc}
\hline Kriteria & Interval & Frekuensi & Prosentase \\
\hline Amat Baik & $90-100$ & 2 & 10.00 \\
Baik & $80-89$ & 3 & 20.00 \\
Cukup & $51-79$ & 10 & 70.00 \\
Kurang & $0-50$ & & \\
Jumlah & & & 100.00 \\
\hline
\end{tabular}

Hasil penelitian menunjukkan bahwa gambaran umum performa wasit diperoleh $10 \%$ berada pada kategori amat baik, $20 \%$ berada pada kategori baik, dan $70 \%$ berada pada kategori cukup. Hal ini menunjukkan bahwa secara umum performa wasit berada pada kategori cukup.

Tabel 4 Hasil Uji Korelasi Mental Toughness Correlations

\begin{tabular}{clcc}
\hline & & Mental Toughness & Performa Wasit \\
\hline Mental & Pearson Correlation & 1 & $.812^{* *}$ \\
Toughness & Sig. (2-tailed) & & .000 \\
& $N$ & 15 & 15 \\
\hline
\end{tabular}

1) Melihat signifikansi hubungan: antara Variabel Mental Toughness dengan Performa Wasit. Berdasarkan output di atas, diketahui nilai signifikansi atas Sig.(2-tailed) sebesar 0,000. Karena nilai Sig.(2-tailed) 0,000 0,05, maka artinya ada hubungan signifikan antara variabel mental toughness dengan performa wasit.

2) Melihat kekuatan hubungan: antara Variabel Mental Toughness dengan performa wasit. Dari output di atas, diperoleh angka koefisien korelasi sebesar 0,812. Artinya, tingkat kekuatan hubungan (korelasi) antara variabel mental toughness dengan performa wasit adalah sebesar 0,812 atau tinggi.

3) Melihat arah hubungan: antara Variabel Mental Toughness dengan Performa Wasit. Angka koefisien korelasi pada hasil di atas, bernilai positif, yaitu 0,812. Sehingga hubungan kedua variabel tersebut saling berhubungan. Dengan demikian dapat diartikan bahwa mental toughness berhubungan dengan performa wasit saat memimpin pertandingan. 
Tabel 5 Hasil Uji Korelasi Competitive Anxiety Correlations

\begin{tabular}{clcc}
\hline & & $\begin{array}{c}\text { Competitive } \\
\text { Anxiety }\end{array}$ & $\begin{array}{c}\text { Performa } \\
\text { Wasit }\end{array}$ \\
\hline $\begin{array}{c}\text { Competitive } \\
\text { Anxiety }\end{array}$ & Pearson Correlation & 1 & .510 \\
& Sig. (2-tailed) & & .052 \\
& $\mathrm{~N}$ & 15 & 15 \\
\hline
\end{tabular}

1) Melihat signifikansi hubungan: antara Variabel Competitive Anxiety dengan Performa Wasit. Berdasarkan output di atas, diketahui nilai signifikansi atas Sig.(2-tailed) sebesar 0,052. Karena nilai Sig.(2-tailed) 0,052>0,05, maka artinya tidak ada hubungan signifikan antara variabel competitive anxiety dengan performa wasit.

2) Melihat kekutan hubungan: antara Variabel Competitive Anxiety dengan Performa Wasit. Dari output di atas, diperoleh angka koefisien korelasi sebesar 0,510. Artinya, tingkat kekuatan hubungan (korelasi) antara variabel competitive anxiety dengan performa wasit adalah sebesar 0,510 atau korelasi sedang.

3) Melihat arah hubungan: antara Variabel Competitive Anxiety dengan Performa Wasit. Angka koefisien korelasi pada hasil di atas, bernilai positif, yaitu 0,510. Sehingga hubungan kedua variabel tersebut berhubungan. Dengan demikian dapat diartikan bahwa competitive anxiety berhubungan dengan performa wasit saat memimpin pertandingan.

\section{Tabel 6 Hasil Pengujian Regresi Berganda Hasil Uji F}

ANOVA $^{\mathrm{a}}$

\begin{tabular}{|c|c|c|c|c|c|c|}
\hline Model & & $\begin{array}{l}\text { Sum of } \\
\text { Squares }\end{array}$ & Df & $\begin{array}{l}\text { Mean } \\
\text { Square }\end{array}$ & $\mathrm{F}$ & Sig. \\
\hline \multirow[t]{3}{*}{1} & Regression & 864.092 & 2 & 432.046 & 11.775 & $.001^{\mathrm{b}}$ \\
\hline & Residual & 440.308 & 12 & 36.692 & & \\
\hline & Total & 1304.400 & 14 & & & \\
\hline
\end{tabular}

a. Dependent Variable: Performa Wasit

b. Predictors: (Constant), Competitive anxiety, Mental toughness

Berdasarkan tabel 6, diketahui nilai signifikansi adalah sebesar 0,001. Karena 0,001 $<0,05$, dapat disimpulkan bahwa hipotesis diterima atau dengan 
Rahayu Lestari' ${ }^{1)}$, Adi Rahadian ${ }^{2)}$, Aziz Amrulloh ${ }^{3)}$, Muhamad Syamsul Taufik ${ }^{4)}$. Jp.jok (Jurnal Pendidikan. Jasmani,

kata lain mental toughness $\left(\mathrm{X}_{1}\right)$ dan competitive anxiety $\left(\mathrm{X}_{2}\right)$ secara simultan berpengaruh terhadap performa wasit (Y).

Sejalan hasil analisis data diatas bahwa terdapat hubungan antara mental toughness dengan performa wasit karate dalam memimpin suatu pertandingan. Ini berarti semakin tinggi mental toughness wasit selaras dengan performa wasit saat memimpin pertandingan, dan sebaliknya mental toughness wasit rendah, maka performa wasit akan kurang dalam memimpin pertandingan dan pertandingan tidak akan berjalan dengan lancar. (Gantois et al., 2019) menunjukkan penurunan kinerja teknis di atlet/pelatih dan wasih yang lelah secara mental" Jadi, mental toughness sangat berperan dan berpengaruh terhadap performa seorang wasit.

Seorang wasit wajib memiliki mental toughness yang tinggi agar dapat melaksanakan tugasnya secara maksimal. Menjadi seorang wasit itu tidaklah mudah. Seorang wasit harus dapat mengantisipasi situasi yang kurang kondusif misalnya keributan yang timbul pada saat wasit memimpin dan melakukan kesalahan. Oleh karena itu, seorang wasit yang memiliki mental toughness yang tinggi, itu akan memperkecil skala terjadinya kesalahan yang menimbulkan keributan dilapangan. (MG et al., 2019) bahwa segi fisik, teknik, taktik, dan mental untuk menunjang keberhasilan atlet/perangkat pertandingan dalam memperoleh prestasi olahraga yang maksimal. Menurut (Tangkudung, 2018) Salah satu gejala-gejala kejiwaan yang terjadi pada atlet yaitu kecemasan (anxiety). Kejadian-kejadian yang penting sebelum, saat, dan akhir pertandingan dalam olahraga karate sangat dipengaruhi oleh kecemasan; baik atlet, pelatih, wasit, maupun penonton. Karena itu, performa wasit saat memimpin suatu pertandingan akan hancur atau tidak akan berjalan dengan lancar, apabila competitive anxiety tinggi.

Menurut (Kumar, 2016) psikologi seseorang dalam sebuah pertandingan sangat menentukan segalanya. Seorang wasit yang optimal performa dalam pertandingan yang dipimpin maksimal. Pandangan (Tangkudung, 2018) berdasarkan jenisnya, kecemasan dibagi menjadi dua macam yaitu state anxiety dan trait anxiety. State anxiety adalah keadaan emosional yang terjadi mendadak/pada waktu tertentu yang ditandai dengan kecemasan, takut, tegang, dan biasanya kecemasan ini terjadi saat menjelang pertandingan, kecemasan 
lainnya yang terjadi pada atlet biasanya takut gagal dalam pertandingan, takut akan akibat sosial atas kualitas prestasinya, takut cedera atau hal lain menimpa dirinya, takut terhadap agresi fisik baik oleh lawan maupun dirinya, dan takut bahwa kondisi fisiknya tidak akan mampu menyelesaikan tugasnya atau pertandingannya dengan baik. (MS. Taufik, 2019) mengatakan bahwa mental dan konsentrasi merupakan kemampuan olahragawan dalam memelihara fokus perhatiannya dalam lingkungan pertandingan yang relevan. Jadi, competitive anxiety sangat berperan dan berpengaruh terhadap performa seorang wasit. Dengan demikian, seorang wasit itu disarankan menjaga dan memelihara tingkat competitive anxiety rendah. Karena akan memberikan performance terbaik pada saaar memimpin pertandingan.

\section{SIMPULAN}

Hasil penelitian dapat disimpulkan bahwa terdapat hubungan yang signifikan antara mental toughness dan competitive anxiety dengan performa wasit karate dalam memimpin suatu pertandingan. semakin tinggi mental toughness wasit maka performa wasit saat memimpin pertandingan akan sangat baik, namun apabila mental toughness wasit rendah maka performa wasit akan kurang baik dan memimpin pertandingan tidak akan berjalan dengan lancar.

\section{DAFTAR RUJUKAN}

Carlos, L. P., Ezequiel, R., \& Anton, K. (2019). How does Video Assistant Referee (VAR) modify the game in elite soccer?. International Journal of Performance Analysis in Sport, 19(4), 646-653.

Clarasasti, E. I., \& Jatmika, D. (2017). Pengaruh Kecemasan Berolahraga terhadap Motivasi Berprestasi Atlet Bulutangkis Remaja di Klub J Jakarta. Humanitas (Jurnal Psikologi), 1(2), 121-132.

Firmansyah, Y. (2018). Hubungan Antara Kesiapan Mental, Kecemasan, Dan Tingkat Konsentrasi Dengan Performa Wasit Dalam Memimpin Pertandingan Softball (Doctoral dissertation, Universitas Pendidikan I Frigout, J., Laporte, R., \& Lepresle, A. (2017). Pemodelan dan Performa Olahraga di Karate. Jurnal Ilmu Olah Raga, 5 , 332-339.

Gantois, P., Caputo Ferreira, M. E., Lima-Junior, D. D., Nakamura, F. Y., Batista, G. R., Fonseca, F. S., \& Fortes, L. D. S. (2020). Effects of mental fatigue on passing decision-making performance in professional soccer athletes. European journal of sport science, 20(4), 534-543. 
Rahayu Lestari'), Adi Rahadian ${ }^{2)}$, Aziz Amrulloh', Muhamad Syamsul Taufik ${ }^{\text {4) }}$. Jp.jok (Jurnal Pendidikan. Jasmani,

Gaos Sungkawa, M. G., Taufik, M. S., \& Pratama, A. K. (2020). Pengaruh Latihan Lari Interval Dan Latihan Fartlex Terhadap Peningkatan Vo2 Max. Jendela Olahraga, 5(2), 43-51.

García-Santos, D., Gómez-Ruano, M. A., Vaquera, A., \& Ibáñez, S. J. (2020). Systematic review of basketball referees' performances. International Journal of Performance Analysis in Sport, 1-39

Ivinson, A. J. (2001). Society's stake in xenotransplantation. In Quarterly Review of Biology. 76(3). https://doi.org/10.1086/393991

Jannah, M. (2017). Kecemasan dan Konsentrasi Pada Atlet Panahan. Jurnal Psikologi Teori Dan Terapan, 8(1), 53-60.

Jatra, R., \& Fernando, D. D. (2019). The understanding of court tennis rules for participants of licensing tennis umpire training. Jurnal SPORTIF: Jurnal Penelitian Pembelajaran, 5(1), 70-79.

Jose, J., \& Joseph, MM (2018). Citra: Ini efek dan manfaat pada kinerja olahraga dan variabel psikologis: Sebuah studi ulasan. Jurnal Internasional Fisiologi, Gizi dan Pendidikan Jasmani , 3(2), 190-193.

Khan, A., \& Sorate, B. A. (2016). A comparative study of sports competition anxiety within Jimma university male players of different sports. Journal of Tourism, Hospitality and Sports, 17(1), 38-41.

Kumar, A. (2016). A study on mental toughness and sports competition anxiety for male and female basketball players. International Journal of Physical Education, Sports and Health, 3(2), 379-381.

Kuswoyo, D. D., Pramono, H., \& RC, A. R. (2017). Kontribusi Percaya Diri, Konsentrasi dan Motivasi terhadap Kinerja Wasit Persatuan Sepak Bola Seluruh Indonesia Provinsi Sumatera Selatan. Journal of Physical Education and Sports, 6(3), 241-247.

Rahadian, A., \& Suryakancana, U. (2020). Kebijakan Olahraga Dalam Pemerintahan Lokal: Sebuah Penelitian dalam Merumuskan Rancangan Induk Pembangunan Olahraga Nasional. November 2018.

Rahman, F. A., Kristiyanto, A., \& Sugiyanto, S. (2017). Motif, Motivasi, Dan Manfaat Aktivitaspendakian Gunung Sebagai Olahraga Rekreasi Masyarakat. Multilateral Jurnal Pendidikan Jasmani Dan Olahraga, 16(2), $143-153$.

Setiawan, A., Jannah, M., \& Wijono, W. (2018, November). Pengaruh Latihan Relaksasi Secara Progresif Terhadap Penurunan Kecemasan Pada Pembinaan Prestasi Sepak Takraw. In Prosiding Seminar Nasional IPTEK Olahraga (SENALOG), 1(1).

Susanto, N. (2019). Pengaruh Motivasi Kerja, Kepuasan Kerja, Dan Disiplin Kerja Terhadap Kinerja Karyawan Pada Divisi Penjualan Pt Rembaka. 
Agora, 7(1).

Tangkudung, J. (2018). Sport Psychometrics Dasar-dasar dan instrument Psikometri. Depok: Rajagrafindo persada.

Taufik, M. S. (2019). Hubungan Tingkat Konsentrasi Dengan Keterampilan Bermain Futsal Unit Kegiatan Mahasiswa Futsal Universitas Suryakancana. Gladi: Jurnal Ilmu Keolahragaan, 10(02), 68-78. 